Religious Studies (2022) 58, 297-326 @ The Author(s), 2020. Published by Cambridge University Press doi:10.1017/S0034412520000359

\title{
Theorizing about faith with Lara Buchak
}

\author{
DANIEL HOWARD-SNYDER \\ Department of Philosophy, Western Washington University, Bellingham, WA, 98229, \\ $U S A$ \\ e-mail: Daniel.Howard-Snyder@wwu.edu
}

DANIEL J. MCKAUGHAN (1)

Department of Philosophy, Boston College, 351N Stokes Hall, Chestnut Hill, MA 024673806, USA

e-mail: daniel.mckaughan@bc.edu

\begin{abstract}
What is faith? Lara Buchak has done as much as anyone recently to answer this question in a sensible and instructive fashion. As it turns out, her writings reveal two theories of faith, an early one and a later one - or two versions of the same one if you like. In what follows, we aim to assess those theories with an eye to highlighting both their good- and bad-making features, marking choice points for theorizing about faith along the way, and defending the choices we make. The result is an alternative theory of faith, one that we hope extends our common pursuit of understanding what faith is.
\end{abstract}

What is faith? This question is especially important for Christians since the New Testament is stuffed with the idea that God prizes faith as a human response to God, an idea affirmed by other religious traditions as well. Moreover, this question is important for all of us because faith plays a defining role in relationships we all value highly, namely relationships of mutual faith and faithfulness, which permeate society and even extend into the grand project of human inquiry, the project of understanding ourselves, our world, and our place in the world. It behoves us, therefore, to get clear on what faith is.

Lara Buchak has done as much as anyone recently to answer our question in a sensible and instructive fashion. As it turns out, her writings reveal two theories of faith, an early one and a later one (or, if you like, two versions of the same theory). In what follows, we aim to do three things. First, we will state and assess Buchak's early theory, highlighting both its good-making and bad-making features. Second, we will do the same for her later theory, noting improvements on the early one. 
Third, we will mark various choice points in theorizing about faith, and we will argue for specific choices at those points, culminating in what we regard as a better, alternative theory of faith. Our critical aims, therefore, are ultimately constructive. By theorizing about faith with Lara Buchak, we aim to contribute to our common understanding of what faith is.

\section{Buchak's early theory}

In her first published paper on faith, Buchak aims to give an account of propositional faith expressed by action. Before we plunge into the details, a word on propositional faith is in order.

In English, propositional faith is expressed by sentences of the form 'S has faith that p', as when an avid Patriots fan has faith that New England will win the Super Bowl, despite being down by 25 with 8:31 left in the third quarter. Propositional faith relates a person to a proposition. Philosophers distinguish it from relational faith. Relational faith is expressed in English by sentences of the form 'S has (puts, maintains) faith in $\mathrm{x}^{\prime}$. It paradigmatically inaugurates and perpetuates a certain relationship between people, one in which one person relies on, or is disposed to rely on, another in a certain way. We say 'in a certain way' because you might have faith in your children as students but not as pilots. We can also have faith in things other than people, e.g. abilities, ideals, institutions, kayaks, etc.

We may well wonder how relational faith is related to propositional faith. Buchak suggests that the former is best understood as the latter or, more tentatively, that such an understanding is desirable. She proposes that 'I have faith in your abilities is equivalent to I have faith that you are able to do such-and-such' and 'to have faith in a person is to have faith that some facts about her obtain'. ${ }^{1}$

Like Buchak, we aim for a theory of faith that unifies the full range of faith-phenomena in the simplest way possible. However, in our view, understanding relational faith as propositional faith is not the way to achieve such unity and simplicity, nor is it desirable. Relational faith is a relation that paradigmatically holds between two or more people, whereas propositional faith is a relation that holds between a person and one or more propositions. Understanding relational faith as propositional faith omits the object of faith. For you can no more put your faith in someone unless they exist than you can put your noodles in a bowl unless it exists; but you can have faith that certain facts about them obtain even if they do not exist just as you can have faith that certain facts about a bowl obtain even if it does not exist.

Even if relational faith cannot be understood as propositional faith, the latter is worthy of inquiry in its own right. (And from here on, all talk of faith will be talk of propositional faith unless otherwise stated.) However, as we indicated, Buchak (2012) does not take faith simpliciter as her target of theorizing; rather, her target is faith expressed by action A. Buchak's early theory, what she calls 'my final analysis', goes as follows: 
Buchak's early theory. A person has faith that $X$, expressed by $A$, if and only if that person performs act $A$ when there is some alternative act $B$ such that he strictly prefers $A \& X$ to $B \& X$ and he strictly prefers $B \& \sim X$ to $A \& \sim X$, and the person prefers \{to commit to A before he examines additional evidence $\}$ rather than \{to postpone his decision about $A$ until he examines additional evidence\}. ${ }^{2}$

We have five minor concerns about Buchak's early theory.

First, in her commentary, Buchak suggests that faith is either context-dependent or degreed, i.e. stronger or weaker. ${ }^{3}$ In later work, she opts for faith coming in degrees. ${ }^{4}$ We agree. Faith can be stronger or weaker depending on, among other things, which actions express one's faith. Suppose your faith in God is expressed by regular prayer but not by giving your life to the poorest of the poor in Calcutta; then, all else being equal, Mother Teresa's faith in God was stronger than yours. Buchak's early theory thus tacitly allows for comparative assessments of the strength of people's faith that $\mathrm{X}$, as measured by the kinds of actions that they are willing to perform and by the extent to which they are willing to take more or fewer risks on $\mathrm{X}$ without examining additional evidence. But it's also fine methodologically to work out a theory of something that comes in degrees by first working it out in non-degreed terms. In what follows, faith's coming in degrees will remain tacit.

Second, Buchak later says of herself that, in Buchak (2012), she 'argued that to have faith in a proposition consists, roughly speaking, in stopping one's search for evidence and committing to act on that proposition without further evidence'; and that, in Buchak (2012), she gave 'a practical account of faith' according to which 'faith that $p$ requires that one is willing to take risks on $p$ - that one is willing to choose acts that do best if $p$ is true over acts that do best if $p$ is false'. ${ }^{5}$ Note well: she omits the expressed by $A$ qualification both times. It appears, therefore, that Buchak took herself to be theorizing about faith simpliciter in Buchak (2012), or at least that the explicit restriction to faith expressed by $A$ was not critical to the target of her theorizing, as also indicated in other post-2012 writings. ${ }^{6}$

This strikes us as sensible. That's because, as we will see, conative and cognitive attitudes are also essential to faith and none is more faith-expressive than the other. Better to have a theory of faith simpliciter than different theories for faith expressed by action A, faith expressed by pro-attitude $P$, or faith expressed by cognition $C$.

In light of Buchak's willingness to drop the 'expressed by A' restriction, we will take Buchak's early theory to be a theory of propositional faith simpliciter, and so, at a first pass, we give it the following (logically equivalent) reading:

A person has faith that $X$ if and only if there is some act $A$ such that his performing $A$ expresses his faith and he performs $A$ when . .

where the ellipsis is filled with what follows 'when' in the original quoted above, and which allows for comparative assessments of the strength of a person's faith that $\mathrm{X}$ just as the original does. 
Our third minor concern is that you can have faith even while you are sound asleep, and so you can have faith even while you perform no faith-expressive action; but you can satisfy the right-hand side of the biconditional only while you perform some faith-expressive action. Buchak makes it clear in her commentary, however, that this is not her intent. What matters, she writes, is that you are disposed to perform such a faith-expressive act. ${ }^{7}$ This might usefully be made explicit.

Fourth: there are minor technical difficulties. For example, on the face of it, the theory implies that no one can have faith unless they prefer one set over another. However, one could have faith even if there were no sets; and, even if there are sets, one could have faith even if no set was an object of their preferences. We expect that Buchak does not intend to incur such ontological commitments and that she tailored the statement of her theory to an audience of decision theorists. In any case, we will remove the curly brackets in our discussion so that there is no misunderstanding induced by the terminology. ${ }^{8}$ Moreover, only statements or propositions can enter into the conjunction relation, in which case ' $A \& X^{\prime}$, ' $B \& X$ ', and their ilk are ill-formed since $A$ takes the name of an act as a substitution instance. In this connection, note that, in her commentary on the requisite preferences, Buchak writes: 'a person can have faith that $\mathrm{X}$ only if he cares whether $\mathrm{X}$ is true or false, and presumably this is because the person would like to perform the act if $\mathrm{X}$ is true but would like to do some other act if $\mathrm{X}$ is false', and in an anthologized version of Buchak (2012), she says that an act A constitutes taking a risk on $p$ 'just in case there is some alternative available act $\mathrm{B}$ such that $\mathrm{A}$ is preferred to $\mathrm{B}$ on the supposition that $p$ holds and B is preferred to A on the supposition that not- $p$ holds' ${ }^{9}$ No troublesome conjunctions here. Since Buchak seems happy to express her view without them, we will do the same.

Fifth: Buchak puts her theory in terms of a biconditional. We have two concerns on this score. (i) A biconditional can be true but possibly false. We suspect that Buchak intends a necessarily true biconditional. Otherwise, it is possible that someone has faith even if they do not satisfy the right-hand side and, presumably, she does not want to allow that. (ii) In general, a necessarily true biconditional can fail to be explanatory, can fail to shed light on what something is. We suspect that Buchak intends her theory to explain why someone has faith when they do or, in an idiom we prefer, one that tells us what it is for someone to have faith. We are encouraged to read her in this way by her later writings, where she says she means to give a theory of 'The Nature of Faith' and she takes herself to be answering the question 'What is Faith?'. ${ }^{10}$

Taking these five minor concerns into account (and using $\mathrm{p}$ as a propositional variable, $\mathrm{S}$ as a personal variable, and $\mathrm{A}$ and $\mathrm{B}$ as action variables, and eliminating gendered pronouns), we get

Buchak 2012*. For $\mathrm{S}$ to have faith that $p$ is (1) for $\mathrm{S}$ to be disposed to perform some act $\mathrm{A}$ the performance of which would express their faith that $p$, and 
(2) for there to be some alternative act B such that (a) S prefers to perform A over performing $\mathrm{B}$, given $p$, (b) S prefers to perform $\mathrm{B}$ over performing $\mathrm{A}$, given not- $p$, and (c) $\mathrm{S}$ prefers to commit to performing $\mathrm{A}$ before they examine additional evidence rather than to postpone their decision about A until they examine additional evidence.

We will focus on Buchak 2012* since, for the reasons given, it seems to us to be the best way to interpret Buchak's early theory and it aligns with the spirit of her later remarks about the view. ${ }^{11}$

\section{Assessing Buchak 2012*}

Before we turn to three major concerns about Buchak 2012*, we will highlight five good-making features.

\section{Good-making features of Buchak 2012*}

First, whatever else faith is, it is active and reliant. If you have faith that $p$, then you will be disposed to act on $p$; specifically, you will be disposed to rely on $p$ 's being true. ${ }^{12}$ On Buchak 2012*, faith does precisely that: faith disposes you to rely on $p$ 's being true in just the way indicated in both clauses of the theory.

Second, Buchak 2012* unifies faith across secular and religious contexts. The faith someone has when they have faith that their troubled adolescent daughter will flourish as an adult is the same sort of psychological state as the faith they have when they have faith that God will heal their son.

Third, Buchak 2012* does not confuse faith with faithfulness, unlike some recent theories. ${ }^{13}$ However, Buchak sometimes refers to someone who has faith as 'the faithful person', 'the truly faithful', and 'the faithful agent'. ${ }^{14}$ But, 'faithful' does not mean 'has faith' or 'is full of faith' or 'is especially characterized by faith' or anything of the sort. Rather, as William Alston observes, '[a] faithful person is one who is worthy of faith being reposed in him or her, trustworthy, reliable, loyal, steadfast, constant, and so on'. ${ }^{15}$ So, to speak of people who have faith as faithful people is misleading, at best, and identifies faith and faithfulness, at worst.

Fourth, Buchak 2012* does not imply that you have faith that $p$ only if you believe $p$, or only if you are certain that $p$, or only if you are not in doubt about whether $p$, or only if you have insufficient evidence to believe $p$, or only if it is caused by an act of will. It thereby avoids the excesses of Thomistic and other cognitively demanding theories of faith. ${ }^{16}$

Finally, Buchak 2012* allows the tools of decision theory to be readily applied in the assessment of the practical rationality of faith-expressive actions.

\section{Three major concerns about Buchak 2012*}

We have three major concerns about Buchak 2012*. By our lights, each concern poses a choice point for pistologists, i.e. for those who theorize about 
the nature and value of faith and nearby psychological phenomena. We will give reasons for the choices we make.

\section{Faith involves some positive conative state or other}

Buchak says that 'the truth or falsity of the proposition(s) involved is ordinarily a matter of importance to the actor ... We do not attribute faith to a person unless the truth or falsity of the proposition involved makes a difference to that person.' ${ }^{17}$ 'Ordinarily' is too weak, but if 'unless' expresses a necessary condition, then we agree: necessarily, you have faith that $p$ only if the truth or falsity of $p$ is a matter of importance to you, only if you care whether or not $p$ is true, only if the truth or falsity of $p$ makes a difference to you. This goes in the right direction; but we need to exercise caution in two ways.

First, the truth or falsity of $p$ can be a matter of importance to you even when you are consumed by a desire for $p$ to be false, and you can care whether or not $p$ is true when you are totally hostile to its being true, and the truth or falsity of $p$ can make a difference to you even when you are wholly against it being the case. Here's a fix: $\mathrm{S}$ has faith that $p$ only if $\mathrm{S}$ cares with positive valence that $p$.

Second, we need to ensure that our theories of faith include a caring condition. So far as we can tell, there is none in Buchak 2012* (or in Buchak's early theory). The only items that might express the caring condition are two preferences: preferring to act one way over another, given $p$, and preferring to act the second way over the first, given not- $p$. But they don't add up to caring with positive valence that $p$. We prefer eating live worms over eating live slugs, given that the worms are fresher than the slugs; moreover, we prefer eating live slugs over eating live worms, given that the worms are not fresher than the slugs; but it doesn't follow that we care with positive valence that we eat live worms. Quite the contrary. But we still satisfy the preference conditions of Buchak 2012*. Therefore, we'll need to add a caring condition.

One might ask: why add a caring condition in the first place? According to Buchak, we should add it because 'it does not seem apt to state that I have faith that the Nile is the longest river in Egypt, because I do not care whether or not this is true'. ${ }^{18}$ The argument here could be clearer. After all, even if it is inapt to state that she has faith that the Nile is the longest river in Egypt, how is that relevant to the claim that she does not have faith that it is the case?

Perhaps Buchak has in mind a conjunction test argument, which relies on a defeasible link between apt and inapt, or felicitous and infelicitous, usage of English words, on the one hand, and the contents of the concepts associated with standard usage of those words, on the other hand. Consider the following cases:

Case 1. Suppose we were talking about the COVID-19-induced sour economy and our retirement portfolios which we'll be relying on in a couple years, and I said: 'Well, the bottom line is that, although I am 
completely indifferent as to whether I'll recover my 50\% losses, I still have faith that I will recover them.'

Case 2. Imagine that I confide in you, my friend, about my rocky marriage, and along the way I say: 'Even though things are sketchy between us, I still have faith in her as my wife, although to be honest with you, I couldn't care less whether she comes through on that score. In fact, the thought of her as my wife makes me gag.'

Case 3. Suppose I disclosed to you in a heart-to-heart exchange: 'You know, it used to really matter to me whether there was a God; but now, . . now, I just can't drum up any enthusiasm for the prospect. In fact, I don't give a shit. But I still have faith that there's a God.'

In each of these cases - which can be easily multiplied - you would be perplexed, bewildered, or suspicious about what I said. Even though what I said was grammatical, it was weird, inapt, inappropriate, inapposite, infelicitous; take your pick. What I said cries out for explanation. That's because, given standard uses of 'faith that' and the variety of ways we express whether we care about the truth of some proposition in modern English, being completely indifferent, or totally hostile, or otherwise lacking anything in virtue of which we care with positive valence, is at odds with having faith. But in that case, our concept of faith precludes one from having faith unless one cares with positive valence. And that fact about our concept of faith gives us defeasible reason to think that caring with positive valence is essential to faith. Perhaps Buchak had something like this in mind, which seems reasonable.

Four other things might be said in favour of the caring condition on faith.

First, it helps to distinguish faith from other mental states sometimes mistaken for it. ${ }^{19}$ For example, when Long John Silver and his crew give you the black spot and threaten to kill you shortly after sundown if you don't hand over the treasure map, you might believe that they will follow through, but you lack faith that they will. That's because faith, unlike belief, involves a positive conative state towards the truth of the target proposition and you lack any such state.

Notice that you can have mixed feelings about the truth of the target proposition. Suppose that, as a revolutionary charged with treason, you are vigorously opposed to being executed by guillotine. Further, you don't want it to be true that the blade will bring your life to an end swiftly. Yet, in those circumstances, you could still have faith that the blade will bring your life to an end swiftly. After all, given the only alternative - namely, let's suppose, that the blade is dull and would only hack half way through your neck, and would need to be raised and lowered a number of times before severing your head from your body - you understandably have mixed feelings. But that's enough. All it takes to satisfy the caring condition on faith that the blade will bring your life to an end swiftly is for you to care at least somewhat with positive valence that it do so. 
Second, you cannot have faith that $p$ unless you regard $p$ 's truth as good or desirable; but you cannot regard $p$ 's truth as good or desirable unless you care with positive valence that $p$, at least somewhat; so you have faith that $p$ only if you care with positive valence that $p .^{20}$ Of course, this reason affirms the notoriously contentious premise that you cannot regard $p$ 's truth as good or desirable unless you care with positive valence that $p$, which will appeal to many but not all readers.

Third, like other complex propositional attitudes (e.g. fear and hope) faith motivates behaviour. All you need to know to understand why the hiker beats the grass as they walk through the meadow is that they fear that rattlesnakes lie nearby. All you need to know to understand why the climber waves towards the sky is that they hope that they'll catch the eye of the search-and-rescue pilot. Fear and hope have built into them what it takes to motivate behaviour; that's why they explain it. The same goes for faith. All you need to know to understand why Yehuda continues to study Torah despite his doubt and fatigue is that he has faith that the basic Jewish story is true. Like fear and hope, faith motivates behaviour; that's why it explains it. But cognition alone cannot motivate behaviour. Like fear and hope, therefore, faith has something conative built into it, something in virtue of which one cares with positive valence that the target proposition is true. ${ }^{21}$

Fourth, one cannot have faith that something is so unless one has a tendency to feel some negative emotion upon learning that one's faith is disappointed, e.g. dismay. Further, one cannot have faith unless one has a tendency to feel some positive emotion upon learning that one's faith is vindicated, e.g. satisfaction. But if that's right, then one cannot have faith that something is so unless one cares at least somewhat with positive valence that it is so. ${ }^{22}$

\section{Faith involves resilience}

When you put and maintain faith in someone, you'll be disposed to stick to it in the face of challenges to living in light of it, at least somewhat. The same goes for propositional faith. It has a sort of stickiness to it, especially when things get tough. In the past, we have thought of this stickiness in terms of resilience, but it can be anything in virtue of which you are disposed to hang in there: perseverance, grit, fortitude, tenacity, stick-to-itiveness, pluck, moxie, spunk, etc. Of course, faith's stickiness need not be like gorilla-glue, but it needs to be at least somewhat adhesive.

Buchak 2012* has no stickiness. To be sure, on Buchak 2012*, you have faith only if you possess the preferences indicated there; however, possessing them does not even slyly suggest that you will be at all resilient, perseverant, gritty, tenacious, stick-to-itive, or even a wee bit gluey in the face of challenges to living in light of your faith.

Objection: in Buchak 2012* and in Buchak's early theory, we see the preference to commit to performing A before one examines additional evidence rather than to 
postpone one's decision about A until one examines additional evidence. This commitment is a form of stickiness.

By way of reply, two points. First, we agree that committing to perform A instead of postponing one's decision about A until examining further evidence is one way for faith to be sticky. However, there are other ways, and they suffice to satisfy faith's stickiness condition. So this way is not necessary. We will defend this claim later. For now - and this is our second point - we note that, even if you prefer to commit to performing A instead of postponing your decision about A until you examine further evidence, it does not follow that you commit to performing A. Preferring to commit to A is not committing to perform A, nor does it entail committing to perform A. We prefer to commit to eating a fresh slug instead of a bucketful of rotting worms, but we do not thereby commit to eating fresh slugs. Granted: in her commentary, Buchak repeatedly speaks of committing to A rather than speaking of preferring to commit to A. ${ }^{23}$ Unfortunately, preferring to commit to performing A made it into her 'final analysis', not committing to perform A, perhaps another result of speaking to an audience of decision theorists.

We may well ask: why suppose that faith is sticky or, as we tend to say, resilient in the face of challenges?

First of all, it's something of a platitude that faith is not flighty, shaky, wobbly, weak-kneed, or soft-bellied. Unless you're disposed at least somewhat to hang in there, continuing to rely on $p$ 's being true despite obstacles, impediments, and challenges to doing so, you don't have faith.

Second, we might consider the role faith plays in forming and maintaining relationships of mutual faith and faithfulness. With respect to relational faith, Ryan Preston-Roedder observes three sources of value. ${ }^{24}$ (i) When you put your faith in someone, as a spouse, or a friend, or the like, you are more likely to see and appreciate their potential and value in these capacities. (ii) When you put your faith in someone, in a certain capacity, and they recognize it, they are more likely to live up to your favourable view of them because your approval of and reliance on them gives them additional reason to come through for you in that capacity. (iii) When you put your faith in someone, there's a sense in which you cast your lot with them; you make yourself vulnerable to them and you rely on them to respond faithfully. If they do respond faithfully, the result is a sort of solidarity, a solidarity that can increase when they reciprocate the faith you have put in them by putting their faith in you, and you respond faithfully. These observations make sense of Teresa Morgan's claim that, in the ancient Graeco-Roman world, faith played a crucial role in forming and maintaining relationships of mutual faith and faithfulness 'at every socio-economic level', 'relationships of wives and husbands, parents and children, masters and slaves, patrons and clients, subjects and rulers, armies and commanders, friends, allies, fellow-human beings, gods and worshippers, and even fellow-animals'. ${ }^{25}$

Now to the point. Putting your faith in someone can help to promote and sustain valuable relationships in these three ways only if it is at least somewhat resilient in 
the face of challenges of various sorts. By way of illustration, unless the faith you put in your spouse can withstand the strains of marriage, your faith in them won't make these valuable things more likely. If you are disposed to pack your bags and head out of the door at the first sign of them not coming through as a spouse, your 'faith' in them will not make it more likely that you will see them as a spouse favourably, or that they will see themselves as a spouse favourably and act accordingly, or that you both experience marital solidarity. Nor will the relationship benefit from ways in which resilient reliance itself contributes to stability and security. ${ }^{26}$

And what goes for relational faith goes for propositional faith. After all, wouldn't it be surprising if relational faith was resilient while propositional faith was not, as though merely changing the object resulted in a different attitude altogether? Moreover, many opinion-makers (e.g. Richard Dawkins) routinely complain that people who have faith that some religious story is true are stiff-necked, mulish, pig-headed, and otherwise given to obstinacy. They're right, in this respect: propositional faith is resilient in the face of challenges. Further, all else being equal, we prefer a unified theory of faith, one that treats propositional faith and relational faith similarly. At any rate, we see no reason to suppose there's a difference on this score.

Since faith necessarily involves resilience in the face of challenges to living in light of its object being true, we have a fifth reason to think that it necessarily involves caring with positive valence. ${ }^{27}$ That's because, necessarily, we are resilient in the face of challenges to living in light of something only if it matters with positive valence to us, at least somewhat. Thus, for example, we can understand the resilience of a mother's faith that her son is innocent when he's charged with a crime if it matters to her with positive valence that her son is innocent. Likewise, we can understand the resilience of the faith of the paralytic's friends that Jesus will heal him when the crowd prohibits an audience if it matters to them with positive valence that Jesus heals him. But, absent anything in virtue of which we care with positive valence that $p$, we cannot explain faith's resilience.

Faith that $\mathrm{p}$ involves a positive cognitive attitude towards $\mathrm{p}$

On Buchak 2012* (as well as Buchak's early theory), you can have faith that $p$ no matter what cognitive attitude you have towards $p$. Whether you have faith that $p$ floats free-entirely free-of whether you believe $p$ or disbelieve $p$, whether you are certain of $p$ or certain of not- $p$, whether it seems obvious that $p$ or it seems obvious that not- $p$, etc. ${ }^{28}$ And the same goes for cognitive actions. On Buchak 2012*, whether you have faith that $p$ floats free-entirely free-of whether you accept $p$ or reject $p$, whether you judge $p$ to be true or you judge $p$ to be false, whether you assent to $p$ or dissent from $p$, etc. But here's the rub: it is a platitude that you can't have faith that $p$ if you flat-out disbelieve $p$, and the like. Faith requires a more positive cognitive attitude towards its object. 
Perhaps several comments on the idea of a positive cognitive attitude will clarify what we have in mind. ${ }^{29}$

First, two platitudes among others govern theorizing about faith: (i) faith is incompatible with disbelief and, relatedly, (ii) faith requires a belief-like attitude. ${ }^{30}$ In light of the dispute between those who affirm and those who deny that you can have faith that $p$ only if you believe $p$, we need a neutral way to speak of the sort of cognitive attitude faith that $p$ requires, while respecting (i) and (ii): 'positive cognitive attitude' lends itself to the task.

Second, a positive cognitive attitude falls on the cognitive side of the line between the cognitive and the conative and/or volitional; the line between thought and desire and/or will.

Third, a positive cognitive attitude is representational: it represents the world as being a particular way by virtue of its content.

Fourth, we distinguish paradigm cases of positive, negative, and neutral cognitive attitudes. Believing $p$ and disbelieving $p$ are both cognitive attitudes but, of the two, only believing $p$ is a positive cognitive attitude towards $p$. Disbelieving $p$ (i.e., believing not- $p$ ) is a positive cognitive attitude towards not- $p$, but a paradigmatically negative attitude towards $p$. Some cognitive attitudes are neither positive nor negative, e.g. entertaining the proposition that all platypi are monotremes.

Fifth, positive cognitive attitudes have a mind-to-world direction of fit: a positive cognitive attitude towards $p$ is how it ought to be only if $p$ is true. Just as it is the job of a map to represent the territory correctly, so it is the job of a positive cognitive attitude to represent reality correctly. If either fails, the defect lies with it, not reality.

Sixth, a cognitive attitude towards $p$ is positive in that one who has it takes a stand on behalf of $p^{\prime}$ s truth. To take a stand on behalf of $p^{\prime}$ s truth at least partly consists in a complex dispositional state, one we would antecedently expect to be congruent with taking a stand on behalf of $p$ 's truth.

Seventh, a positive cognitive attitude is alethically sensitive: no one has a positive cognitive attitude towards $p$ unless it responds to their grounds for the truth of $p$. Their response need not be conscious or deliberative; it might only be implicit and automatic. (Note well: one way for a positive cognitive attitude towards $p$ to be alethically sensitive is for it to be evidence-sensitive, i.e. for it to reflect one's response to the evidence for the truth or falsehood of $p$. There might be other ways.)

Eighth, we might be tempted to think that a cognitive attitude towards $p$ involves taking a stand on behalf of the truth of $p$ only if its owner has a tendency to outwardly affirm $p$ when asked whether $p$ and a tendency to inwardly affirm $p$ when $p$ is brought to mind. That's how things go for belief that $p$. But there are ways to take a stand on behalf of the truth of $p$ that do not involve those two tendencies. Consider someone who lacks those two tendencies but who has a tendency to outwardly affirm and inwardly affirm that $p$ is likely, or that $p$ is more likely than not, or that $p$ is twice as likely as each of the only three credible contraries 
to $p$, among other propositions that are 'thinner' than $p$. Moreover, they have a tendency to use $p$ as a premise in practical and theoretical reasoning and, more generally, a tendency to rely on $p$ 's being true as they conduct their lives. Furthermore, suppose these tendencies are, in no small part, a response to their grounds for the truth of $p$. If the other conditions for having a positive cognitive attitude are met, their psychology constitutes taking a stand on behalf of the truth of $p$, although tendencies distinctive of belief that $p$ are absent.

So: we submit that faith that $p$ requires a more positive cognitive attitude towards $p$ than disbelieving $p$. Indeed, we submit that it requires a positive cognitive attitude towards $p$ as understood above.

Perhaps a positive cognitive attitude enters Buchak 2012* by way of its triple reference to preferences. However, none of Buchak's writings about preference intimate that it involves any cognitive attitude, positive or otherwise; nor does a cognitive attitude enter by way of taking a risk on $p$ since 'an act A constitutes an individual's taking a risk on $p$ just in case for some alternative available act $\mathrm{B}, \mathrm{A}$ is preferred to $\mathrm{B}$ under the supposition that $p$, and B is preferred to A under the supposition that not$p^{\prime}$, and there's no positive cognitive attitude in that. ${ }^{31}$

In her commentary on Buchak's early theory, Buchak writes: 'when a person has

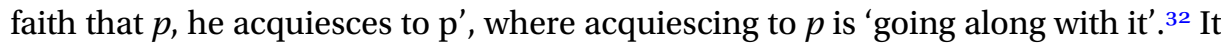
is difficult to see where this condition shows up in Buchak's early theory. More importantly, when, for the sake of your kids on Christmas Eve, you go along with the proposition that you are Santa Claus, you believe it's flat-out false. Apparently, acquiescing to $p$ does not suffice for a positive cognitive attitude towards $p$. Also in her commentary, Buchak says that 'a person cannot have faith in propositions of which he is antecedently certain or for which he has conclusive evidence'. ${ }^{33}$ Perhaps this is the claim that someone has faith that $p$ only if they are uncertain that $p$, which one might see as involving a positive cognitive attitude towards $p$. (But see a later section for potential reservations.) Unfortunately, this claim is omitted from the 'final analysis', i.e. Buchak's early theory quoted above. All we find there are preferences, and no preference does a positive cognitive attitude make.

Upshot: on Buchak 2012* (and Buchak's early theory), no positive cognitive attitude towards $p$ partly constitutes having faith that $p$.

We now turn to Buchak's later theory.

\section{Buchak's later theory}

By our lights, Buchak's later theory substantially improves on the early theory. It goes as follows:

Buchak's later theory. A proposition $X$ is a candidate for faith for a person $S$ if $S$ cares that $X$ holds and is uncertain that $X$ holds on the basis of his evidence alone.

$S$ has faith that $X$ if and only if:

(1) $S$ is willing to take a risk on $X$ without looking for additional evidence; and 
(2) $S$ is willing to follow through on such risky actions even when he receives evidence against $X$.

To the extent that $S$ is willing to perform riskier acts that express his faith, and remains steadfast in the face of stronger counterevidence, he has a higher degree of faith that $X .{ }^{34}$

Notice several things here.

On the positive side, like Buchak's early theory and Buchak 2012*, Buchak's later theory implies that faith is active and reliant, unifies faith across religious and secular domains, avoids the excesses of Thomistic theories and theories of faith that require too much cognitively, renders the tools of decision theory readily applicable, and doesn't confuse faith with faithfulness, although Buchak repeatedly refers to 'the faithful act' as if someone who acts from faith acts from faithfulness, an error pistologists should avoid like COVID-19. ${ }^{35}$ Some of our minor concerns remain, but we will accommodate them as we did before.

One new minor worry: in Buchak's later theory, we find two conditions that are jointly sufficient for a proposition being a candidate for faith. But unless they are also necessary, $p$ could be a candidate for faith for S even if S does not care that $p$ holds and even if $\mathrm{S}$ is not uncertain that $p$ on the basis of their evidence alone. In that case, $\mathrm{S}$ could have faith that $p$ even if $\mathrm{S}$ does not care and is not uncertain.

As for our three major concerns about Buchak's early theory, none arise for Buchak's later theory. First, by way of the caring condition, she adds a positive conative state towards $p$ 's being true, which we can charitably modify by adding that it's caring with positive valence that counts. ${ }^{36}$ Second, by way of the follow-through condition, she adds stick-to-itiveness. Third, by way of the uncertainty condition, she adds a cognitive component: being uncertain that $p$ given one's total evidence. ${ }^{37}$ So, the later theory adeptly avoids all three major concerns about the early theory.

Taking our remarks into account - and treating the two sufficient conditions on being a candidate for faith as necessary and partly constitutive as well, in addition to making tacit (but not forgetting!) the how-faith-comes-in-degrees clause - we get the following result:

Buchak 2018*. For S to have faith that $p$ is for S (1) to care (with positive valence) that $p,(2)$ to be uncertain that $p$ on the basis of their evidence alone, (3) to be willing to (act in such a way so as to) take a risk on $p$ without looking for additional evidence, and (4) to be willing to follow through on those risky actions even when they receive evidence against $p$.

What should we make of Buchak 2018*?

\section{Five major concerns about Buchak 2018*}

Despite its improvement over Buchak 2012*, we have some concerns. Each concern marks a choice point in theorizing about faith. We will give reasons for the choices we make. 


\section{Faith involves resilience in the face of non-evidential challenges}

Consider condition (4) of Buchak 2018*. While a willingness to follow through on faith-expressive actions even when $S$ receives counterevidence is one way to manifest the resilience of faith, it is not the only way. Another is resilience in the face of non-evidential challenges. ${ }^{38}$

Chapter 8 of The Screwtape Letters nicely illustrates the point. C.S. Lewis writes in the voice of Screwtape, a senior devil, to Wormwood, his nephew and a new recruit in the war to undermine God's purposes. Wormwood's 'patient', a recent convert, is experiencing what Screwtape calls a 'trough period', a time of emotional and spiritual 'numbness and poverty'. Wormwood is delighted and writes his uncle expressing 'great hopes that the patient's religious phase is dying away'. In his reply, Screwtape writes that 'the dryness and dullness through which your patient is now going are not ... your workmanship; they are merely a natural phenomenon', an instance of the 'law of Undulation', according to which the closest that humans can approach constancy is a series of emotional troughs and peaks. He continues:

Now it may surprise you to learn that in [the Enemy's] efforts to get permanent possession of a soul, He relies on the troughs even more than on the peaks . . The reason is this . . [A]ll the talk about His love for men, and His service being perfect freedom, is not mere propaganda, but an appalling truth. He really does want to fill the universe with a lot of loathsome little replicas of Himself . . . And that is where the troughs come in. You must have often wondered why the Enemy does not make more use of His power to be sensibly present to human souls in any degree He chooses and at any moment. But you now see that the Irresistible and the Indisputable are the two weapons which the very nature of His scheme forbids Him to use. Merely to override a human will (as His felt presence in any but the faintest and most mitigated degree would certainly do) would be for Him useless ... He is prepared to do a little overriding at the beginning. He will set them off with communications of His presence which, though faint, seem great to them, with emotional sweetness, and easy conquest over temptation. But He never allows this state of affairs to last long. Sooner or later He withdraws, if not in fact, at least from their conscious experience, all those supports and incentives. He leaves the creature to stand up on its own legs - to carry out from the will alone duties which have lost all relish. It is during such trough periods, much more than during the peak periods, that it is growing into the sort of creature He wants it to be. Hence the prayers offered in the state of dryness are those which please Him best. . . He wants them to learn to walk and must therefore take away His hand; and if only the will to walk is really there He is pleased even with their stumbles. Do not be deceived, Wormwood. Our cause is never more in danger than when a human, no longer desiring, but still intending, to do our Enemy's will, looks round upon a universe from which every trace of Him seems to have vanished, and asks why he has been forsaken, and still obeys. $^{39}$

You can see a mini-dark-night-of-the-soul here, but that's not Screwtape's focus. Rather, Screwtape focuses on the 'duties which have lost all relish', a loss of 'emotional sweetness', a state of emotional 'dryness', a diminution of desire. In chapter 9, Screwtape adds that the patient is 'dull and weary', languishing in a 'trough of dullness'; his 'whole inner world is drab and cold and empty'. 
As in their secular relationships of mutual faith and faithfulness, so with God: Christians such as the patient not only experience cognitive troughs, occasions when new counterevidence threatens faith, but also conative troughs, periods of emotional flagging, tiredness, fatigue, dryness, dullness, weariness, drabness, cold, emptiness, and a dimming of desire to do God's will or to follow Jesus. What does the Christian's faith that, for example, the basic Christian story is true, look like in that situation? What does their faith in, for example, Jesus as Lord, look like then? At best, 'No longer desiring, but still intending', they obey; they stand firm in their reliance on the Story, and they live it out by obedience to their Lord, shaping their life accordingly in a variety of ways. That's how, in the conative troughs, they display their willingness to follow through on those faith-expressive actions. Resilience in the face of new contrary evidence is one manifestation of faith's stickiness; another is resilience in the face of new contrary emotions, desires, moods, and other things as well. ${ }^{40}$

\section{A disposition to act on $p$ need not consist in a willingness to act on $p$}

Consider conditions (3) and (4) of Buchak 2018*. What we have to say also applies to (4), but we will focus on (3). As we indicated earlier, underlying the risky action condition is the more general claim that you have faith that $p$ only if you are disposed to act in certain ways, specifically only if you are disposed to rely on $p$ 's being true. But Buchak goes further. It is not enough for you to be disposed to rely on $p$ 's being true; your relying on $p$ 's being true must express itself in risky action and you must stop looking for evidence for $p$. We'll consider these two further restrictions shortly. Here we want to abstract away from them to focus on a third restriction.

At a first approximation, the third restriction is this: it is not enough for you to be disposed to act on $p$; your disposition to act on $p$ must be a willingness to perform the acts that constitute your reliance. 'Faith is tied to action', we're told, in this particular way: 'To have faith in a claim is to be willing to take risks on that claim.' ${ }^{41}$ Abstract away from the nature of the act: taking risks on $p$. Focus on the nature of the disposition to so act: willingness. 'Faith requires a willingness to act on the claim you have faith in.' 42

Things get more complicated, however. Buchak also tells us that 'Faith involves a willingness to commit to acting on the proposition one has faith in', and that 'faith requires committing to a risky act before examining further evidence', and that $\mathrm{S}$ has faith that $p$ only if there is some faith-expressive act A such that $\mathrm{S}$ 'chooses to commit to A before examining additional evidence rather than to postpone her decision about A until she examines additional evidence'. ${ }^{43}$ But these are four distinct mental items:

- a willingness to act on the proposition one has faith in

- a willingness to commit to act on the proposition one has faith in

- committing to act on the proposition one has faith in

- choosing to commit to act on the proposition one has faith in 
Are all four required? Just one? More? Or will any do? And none of these is the one identified in the general claim that faith that $p$ involves being disposed to act on $p$, notably to rely on $p$ 's being true.

We agree that 'faith is linked to action' and we agree with the just mentioned general claim. However: we deny Buchak 2018*'s claim that faith's disposition to act must be a willingness to act. It might be one of the other three items Buchak mentions. Or it might be a strong desire to live in accordance with one's faith, which need not be accompanied by willing, committing, or choosing, or by a disposition to will, commit, or choose. Faith requires a disposition to act, particularly to rely on $p$ 's being true. As for what that disposition consists in, let a thousand flowers bloom.

Buchak disagrees: 'it is important' that this disposition 'concerns commitment rather than simply action - this is what allows [one who has faith] to in fact intake additional evidence, whether for other purposes or accidentally, while continuing to act as faith requires' ${ }^{44}$ We agree that if you commit to perform the faithexpressive act, your commitment will allow you to intake additional evidence while continuing to act as faith requires. But there are other options with the same effect, e.g. a strong desire to live in accordance with one's faith. Elsewhere, Buchak recasts the triple-preference formulation in Buchak's early theory: it 'ought to be formulated in terms of choice' because 'to perform an act of faith is more centrally to choose something than to prefer something'. ${ }^{45} \mathrm{We}$ agree that one way to perform an act of faith is to choose it, but there are other ways, e.g. performing it from a strong enough preference under the right conditions.

Upshot: you have faith that $p$ only if you are disposed to act on $p$, notably to rely on $p$ 's being true. That disposition might consist in a willingness to so act. But it might consist in other things too. Again: let a thousand flowers bloom.

\section{Faith does not necessarily involve uncertainty}

Condition (2) of Buchak 2018* affirms, in short, that faith must be uncertain. In defence of this claim, Buchak writes:

\footnotetext{
We make assertions of faith only when the status of the proposition involved is uncertain or when the evidence we have is inconclusive. For example, when a friend is worried about the outcome of an exam, we might reassure her by saying 'I have faith that you passed'; however, once she shows us that she got an A we would no longer say this. Clearly, this is . . because we now know for certain that she did. For similar reasons, it seems odd to claim to have faith in logical truths.

These considerations suggest that a person cannot have faith in propositions of which he is antecedently certain or for which he has conclusive evidence. ${ }^{46}$
}

We have one point to make about Buchak's line of thought here and three remarks about the more general issue of whether faith must be uncertain.

As for Buchak's line of thought, we agree that it is felicitous for you to say that you have faith that our friend passed, before she shows us that she got an A; 
moreover, we agree that it is infelicitous for you to say it after she shows us that she got an A. However, the asymmetry in view here can just as well be explained by the fact that when you say that you have faith that she passed after, but not before, she shows us that she got an A, you misleadingly imply that you are in a weaker epistemic position than you actually are, which violates a conversational norm: assert the stronger. ${ }^{47}$ Infelicitously reporting faith when you are certain supports the claim that faith entails uncertainty no more than infelicitously reporting belief when you have knowledge supports the claim that knowledge entails not believing - which is to say that it does not support it at all. As for the oddness of claiming to have faith in logical truths when you are certain of them, the same point applies; additionally, we typically don't care with positive valence about their truth. Upshot: what needs explaining here can be explained without recourse to the claim that 'a person cannot have faith in propositions of which he is antecedently certain'.

Now we turn to our three remarks about the general issue of whether faith must be uncertain.

First, an alternative way of accounting for the platitude that faith is risky (from your own point of view). Naturally, one might be tempted to think that we can explain why faith is risky only by recourse to Buchak's claim that faith must be uncertain. However, we can account for the platitude that faith is risky without recourse to Buchak's claim that faith must be uncertain. As a result, the platitude that faith is risky lends no support to Buchak's claim that faith must be uncertain.

Let's distinguish Buchak's claim that

(i) you cannot have faith that $p$ unless you are uncertain that $p$ given your evidence,

from an alternative claim that

(ii) you cannot have faith that $p$ unless you are disposed to act on $p$ when you are uncertain that $p$ given your evidence.

Note that, on Buchak's (i), faith is risky. But faith is risky on (ii) as well. True enough, on (i), faith must be risky while, on (ii), faith need not be risky. Even so, on (ii), faith is virtually guaranteed to be risky. That's because of the general evidential position in which we find ourselves: for any proposition $p$, if we are on this side of the river Jordan, we are in an evidential position that virtually guarantees that we are uncertain that $p$ given our evidence. (Anyone who thinks otherwise would benefit from more quality time with Descartes and his progeny.) Little wonder, then, that for any proposition $p$, if we have faith that $p$, then, if we are on this side of Jordan, we are in an evidential position that virtually guarantees we are uncertain that $p$ given our evidence - in which case faith is risky. And here's the point we want to make: we can use (ii) to account for the platitude that faith is risky, as we just did, just as well as we can use Buchak's (i) to account for it. 
Of course, (ii) cannot account for the claim that faith must be risky. But the modal claim that faith must be risky is not the generic claim that faith is risky, which allows for exceptions. Further, it is the generic claim that is the platitude about faith that needs explaining, not the modal claim, which is not a platitude about faith. Upshot: the platitude that faith is risky does not support Buchak's claim that faith must be uncertain.

Second, a philosophical consideration that tells against Buchak's claim that faith must be uncertain. We begin with the observation that a similar thesis about trust seems implausible. Suppose that you are certain that a friend will keep your secret. A similar thesis says that trusting that they will keep your secret entails uncertainty about whether they will. But in that case, you cannot trust those who are most worthy of your trust, namely those with respect to whom you are certain that they are worthy of your trust - which seems implausible. The same goes for faith. If you have faith that a friend will keep your secret, then, if faith entails uncertainty, you cannot put your faith in those who are most worthy of your faith, namely those with respect to whom you are certain that they are worthy of your faith - which likewise seems implausible.

Third, a theological argument that we put forward as something to think about. The conclusion is that, if God enters into relationships of mutual faith and faithfulness, and if God is cognitively perfect, and if, for any true proposition $p$, cognitive perfection entails certainty about $p$, then faith need not be uncertain. For suppose God enters into a covenantal relationship of mutual faith and faithfulness with the Torlindri, the unfallen humanoid occupants of Perelandra (aka Venus) featured in C. S. Lewis's space trilogy. Then God has faith that they will fulfil the terms of the covenant. Suppose that, as it turns out, it is true that the Torlindri fulfil the terms of the covenant. Then, if God is cognitively perfect, and if, for any proposition $p$, cognitive perfection entails certainty about $p$, when God enters into the covenant, God is certain that they will fulfil its terms. Consequently, when God enters into the covenant, God has faith that they will fulfil its terms even though God is certain that they will do so. Upshot: if God enters into relationships of mutual faith and faithfulness, and if God is cognitively perfect, and if, for any proposition $p$, cognitive perfection entails certainty about $p$, then faith can be certain. Those among us who affirm the antecedent - perhaps after fiddling a bit, e.g. excluding true first-person indexical propositions about others, or insisting that if it is true when God enters the covenant that the Torlindri will fulfil it, then, if God is certain they will, they are neither free nor morally responsible for doing so, or inserting and substituting 'timelessly' in the right places, etc. - have a reason to think that faith need not be uncertain.

\section{One can commit to act without being closed to actionable evidence}

According to condition (3) of Buchak 2018*, you have faith that $p$ only if you are willing to act in such a way so as to take a risk on $p$ without looking for additional evidence. This requirement appears, in some form or other, in all the 
statements of Buchak's theory. She writes: 'faith requires not engaging in an inquiry whose only purpose is to figure out the truth of the proposition one purportedly has faith in'. ${ }^{48}$ Referring to Buchak 2012, she says: 'I argued that to have faith in some proposition consists, roughly speaking, in stopping one's search for evidence and committing to act on that proposition without further evidence.' ${ }^{49}$ Describing her own view in the third person, under the heading 'Faith as Acting Without Looking for Further Evidence', she states:

\footnotetext{
What is distinctive about her view is that faith that $p$ requires that one commit to these [risky] acts without looking for further evidence in the matter of $p$ - at least, without looking for evidence for the sole purpose of deciding what to do - and to maintain one's commitment even in the face of new counterevidence. Thus, faith is a matter of stopping one's search for evidence and taking action..$^{\circ}$
}

Note well: according to Buchak, you can have faith even if you look for evidence so long as you don't look for evidence for the sole purpose of deciding what to do.

Buchak offers two cases to motivate this claim, which we will call Private Investigator and Envelope. ${ }^{11}$ Private Investigator exhibits how checking up on one's spouse to ensure they aren't cheating - for example, by hiring a private investigator, reading their email, or asking their boss if they really were working late last night - seems incompatible with having faith that they aren't cheating. One might respond that even if looking for evidence that is not readily available is incompatible with faith, looking at evidence that is readily available is compatible with faith. Envelope addresses this response: looking at readily available evidence relevant to your spouse's fidelity - for example, opening an envelope that you know contains relevant evidence, even if you only stumbled upon it or they presented it to you also seems incompatible with having faith that they are not cheating. ${ }^{52}$

Do Private Investigator and Envelope help us see the truth of Buchak's claim? Before we answer that question, notice four things about the cases and her claim.

First, both cases involve people who are already in a relationship of mutual faith and faithfulness, i.e. a marriage. The question is whether you maintain faith that your spouse is not cheating if you search for evidence that might be relevant to their cheating (Private Investigator) or if you look at readily available evidence that might be relevant (Envelope). Presumably, the same questions would arise with respect to your coming to have faith, not just maintaining faith you already have. We will focus on maintaining faith and Envelope. If Buchak's claim holds here, it will hold in other cases.

Second, consider the following development of Envelope. Imagine that your job at the company requires you to verify whether employees who claim to have been working late really were working late. Your spouse works at the company. They claim that they were working late with their supervisor. The envelope is on your desk: you know it has information that will verify whether they were working late. Your job requires you to look. You also want to look because it will verify whether they are cheating, which is relevant to your deciding whether to remain married. You look. 
Did you look for the sole purpose of figuring out whether they are cheating and deciding what to do? No. You had two purposes. So Buchak's claim permits your looking at the evidence while having faith that your spouse is not cheating. We doubt Buchak intends this: the case satisfies the letter of her claim, but it violates the spirit. You're not off the hook simply by having an additional purpose. Rather, we suspect, Buchak means that you maintain faith that your spouse is not cheating only if you do not have among your purposes verifying whether they are cheating in order to decide what to do, e.g. remain married. If that's one of your purposes, then you lack faith.

Third, consider another development of Envelope. Everything is the same as before only this time, your only purpose in looking is doing your job. However: you are not closed to looking at evidence that will verify whether they are cheating and deciding what to do on the basis of it, and you know that the envelope contains such evidence. You look.

Did you look in order to verify whether they were cheating and to decide what to do? No. Your only purpose was to do your job. So Buchak's claim permits your looking at the evidence while having faith that your spouse is not cheating. Once again, we doubt Buchak intends this: the case violates the spirit of her claim even if not the letter. You're not off the hook simply by not having among your purposes verifying whether they are cheating in order to decide what to do. Rather, we suspect, Buchak means that you maintain faith that your spouse is not cheating only if you are closed to evidence that is relevant to whether they have cheated, insofar as it might bear on your deciding what to do, e.g. remain married. If you're not closed, then you lack faith.

Fourth, notice the modality of Buchak's claim. Buchak aims to tell us what faith is, to describe its nature. In that case, and given the previous three observations, we attribute the following claim to Buchak:

Closed. Necessarily, if S maintains their faith that $p$, then $\mathrm{S}$ will be closed to looking at further evidence in the matter of $p$, insofar as it might bear on how $\mathrm{S}$ acts.

We suspect Closed is false, for three reasons.

First, even if you are not closed to looking at further evidence in the matter of your spouse's not cheating on you, and even if you are open to it having a bearing on how you act, e.g. remaining married, you might simultaneously be committed to remaining married. It would all depend on what the evidence revealed, exactly. If that's your frame of mind, then you won't be committed come what may to remaining married; your openness prohibits that.

Second, notice that one way in which you might express faith that your spouse is not cheating is by not being closed to looking at further evidence pertaining to the matter, especially if you are open to that evidence having a bearing on what you do, e.g. remaining married. In that frame of mind, perhaps with an eye 
towards vindication of your faith, suppose you look in the envelope and discover that the evidence does not verify that they have been cheating on you. Or, better yet, suppose you look and you discover that it verifies that they have not been cheating on you. In that case, your faith will have been vindicated, not eliminated. ${ }^{53}$

Third, suppose you are married and you have faith that your spouse is not cheating on you, but then a serious question arises as to whether they are cheating. It can be costly for you to postpone deciding whether to remain married. After all, if you delay out of the uncertainty raised by the question, you stand a good chance of depriving yourself of many of the goods of marriage. Further, there is great value in committing to and sticking with a marriage even when such questions arise. However, these goods can be achieved even if you are not closed to looking at the evidence and you are open to deciding against remaining married. And acting on this frame of mind may well lead to a vindication of faith, yet a further good.

We submit that these three points, taken together, shed considerable doubt on Closed. And we expect that, mutatis mutandis, they will apply with equal force to the original Envelope case as well as to Private Investigator.

So far, we have focused on Closed in the context of a personal relationship. We might also focus on Closed in the context of inquiry, e.g. in the sciences, and we might also focus on what any theory of faith that implied Closed might look like as a character trait and whether, so viewed, it could be a virtue. We leave those tasks for another time.

We now turn to the cognitive condition.

\section{Faith and credence}

According to condition (2) of Buchak 2018*, for you to have faith that $p$ is, in part, for you to be uncertain that $p$ on the basis of your evidence alone. But what cognitive attitude, exactly, does Buchak have in mind here? She identifies it as credence. But what is credence? On Buchak's view, credence 'represents the extent to which an individual takes a proposition to be supported by her evidence'. ${ }^{54}$ Elsewhere she writes that, in theorizing about faith, she assumes that belief comes in degrees and that degrees of belief are subjective probabilities which, she says, are a person's estimate of the proposition's truth-value given her evidence. ${ }^{55}$ Moreover, she tells us, we accurately represent someone's credence that $p$ given their evidence as $\operatorname{Pr}(p / e)$, which is read as 'the subjective probability of $p$ given their evidence $e^{\prime} .{ }^{5}$ But how does talk of certainty and uncertainty, the vocabulary in which Buchak 2018* is expressed, map onto talk of credence? Like certainty, credence comes in degrees, and those degrees are represented in the interval $\langle 0,1\rangle$, inclusive, where 0 represents the lowest possible degree of credence and 1 represents the highest. For you to be certain that $p$ on the basis of your evidence alone is for you to have credence 1 that $p$ given your evidence, and for you to be certain that not- $p$ on the basis of your evidence alone is for you to have 
credence o that $p$ given your evidence. Thus, we put Buchak 2018*'s cognitive condition more accurately as follows:

- For $\mathrm{S}$ to have faith that $p$ is, in part, for $\mathrm{S}$ to assign $\operatorname{Pr}(p / e)$ a value other than 0 or 1 .

We have some worries about this.

You can have faith that $\mathrm{p}$ even if you don't assign $\operatorname{Pr}(\mathrm{p} / \mathrm{e})$ a certain value

When Buchak speaks of the cognitive condition, she speaks in terms of someone taking it that the $\operatorname{Pr}(p / e)$ has a certain value or estimating what it is. We will speak in terms of assigning $\operatorname{Pr}(p / e)$ a certain value, as we did above. Three observations are in order.

First, many people lack the intellectual sophistication required to assign a value to $\operatorname{Pr}(p / e)$, not least because they lack the concept of $\operatorname{Pr}(p / e)$. The point here is not that they have the concept but just not under that description. Rather, the point is that they lack the concept under any description. After all, the concept of a subjective conditional probability arguably wasn't understood prior to the seventeenth century, whereas faith was prevalent prior to then. ${ }^{57}$

Second, among those who do have the concept, many have no idea how to assign $\operatorname{Pr}(p / e)$ a certain value. They're nonplussed.

Third, among those who have the concept and have an idea as to how to estimate and assign a value, many refuse to do so, at least for many propositions whose truth they care about. By their lights, they're in no position to estimate and assign a value, and so they refuse to participate in the hubris such activity presupposes.

And here's the point: all such people can have faith. We are confident both that Buchak would agree with this and that she wouldn't regard $\operatorname{Pr}(p / e)$ as representing something that people have to explicitly consider. Moreover, we acknowledge that this kind of objection remains an area of lively discussion about accounts in formal epistemology and, if it is a problem, it isn't a problem for Buchak's account alone (e.g. Hájek \& Lin (2017); Horgan (2017) ). Nor do we mean to suggest that Buchak 2018* couldn't be supplemented with instructions about how to interpret it so as to explain how the view does not preclude unsophisticated, scrupulous subjects from having faith. Further, as Hájek and Lin note, many formal epistemologists 'don't think that we literally have credences; rather, they are theoretical posits of an idealized model' (Hájek \& Lin (2017), 209). That's fine. But it seems fair to ask them, as Horgan does 'to explain to us skeptics why your framework does not badly distort the very psychological and epistemic-normative phenomena you seek to illuminate' (Horgan (2017), 247).

You can have faith that $\mathrm{p}$ even though you lack the capacity to assign $\operatorname{Pr}(\mathrm{p} / \mathrm{e}) a$ value

Buchak 2018* is a theory of what faith is, its nature. On that theory, therefore, necessarily, you have faith that $p$ only if you assign $\operatorname{Pr}(p / e)$ a value. Of course, 
you can assign $\operatorname{Pr}(p / e)$ a value only if you have the capacity to do so. So, on Buchak 2018*, necessarily, you have faith that $p$ only if you have the capacity to assign $\operatorname{Pr}(p / e)$ a value. Let's reflect on this implication briefly.

Intellectual seemings are not credences, and credences are not entailed by intellectual seemings. So it might seem to a person that $p$ even though they are incapable of assigning a value to $\operatorname{Pr}(p / e)$. Now consider the heuristic device of a mental box for each mental-state type. Imagine that, for some strange reason - being youthful, premodern, or the victim of a pesky demon or a gamma ray with quirky powers, etc. - Jacob lacks a credence box, or that Jacob's credence box is empty of anything $p$-ish. In that case, Jacob is incapable of assigning a value to $\operatorname{Pr}(p / e)$, for any $p$. But suppose his seeming box is just fine. It contains $p$, among other propositions. Do we really want to infer that, in that case, Jacob cannot have faith that $p$ ? That's what Buchak 2018* implies. Although it seems to Jacob that there is a God, and although he satisfies faith's other conditions, he lacks faith that there is a God. Why? Because its seeming to him that there is a God is not enough; he must assign a value to $\operatorname{Pr}(\mathrm{God}$ exists/his total evidence). But he lacks that capacity. We ask: doesn't that seem a little excessive? After all, what would assigning a value to $\operatorname{Pr}($ God exists/his total evidence) do that seeming that God exists could not do as faith's cognitive component? Both can involve taking a stand on behalf of the truth of their propositional objects and both can satisfy the other conditions for being a positive cognitive attitude towards $p$, as earlier outlined.

Upshot: propositional faith requires the capacity for some positive cognitive attitude towards its object, but it need not require a capacity for credence. We might also draw a further lesson from this worry and the previous one. In theorizing about faith or components that are partly constitutive of faith, don't be unnecessarily specific about what's required. If there is a given functional role that needs to be filled, often there are lots of suitable candidates that might play the needed role.

You cannot have faith that $\mathrm{p}$ when $\operatorname{Pr}(\mathrm{p} / \mathrm{e})$ is vanishingly close to $o$. . or can you?

On Buchak 2018*, you can have faith that $p$ even if your credence that $p$ given your evidence is vanishingly close to o. It just can't be o. One might worry that this sets the cognitive bar too low for faith.

Let googol be the number 1 followed by 100 zeros $\left(10^{100}\right)$, and let googolplex be the number 1 followed by a googol of zeros $\left(10^{10100}\right)$, and let googolplexian be the number 1 followed by a googolplex of zeros $\left(10^{1010100}\right)$, and let $B C S$ name the propositions that constitute the basic Christian story, and let $E$ be Smith's total evidence, and let Smith identify in such a way that use of feminine pronouns in English is acceptable to her. Now: suppose that, for Smith, $\operatorname{Pr}(\mathrm{BCS} / \mathrm{E})=1$ /googolplexian and $\operatorname{Pr}($ not-BCS/E) = $1-1$ /googolplexian. Suppose further that she cares (with positive valence) that BCS, that she is willing to (act in such a way so as 
to) take a risk on BCS without looking for additional evidence, and she is willing to follow through on such risky actions even when she receives more evidence against BCS. In that case, on Buchak 2018*, Smith has faith that BCS.

Problem: she doesn't, or so one might think. She might yet have hope, and it may well be rational, apt, and even virtuous of her to live in light of that hope. But does she have faith? No, it seems. Why not? Six answers come to mind.

First, isn't it just obvious that Smith lacks faith? In order to have faith, mustn't she have a more positive cognitive attitude towards BCS than this: $\operatorname{Pr}(\mathrm{BCS} / \mathrm{E})=1$ / googolplexian?

Second, consider the following cases:

Case 1. Imagine it's 2008, and we're talking about our retirement plans, and I divulge that I put all my savings in one basket: Bernie Madoff real estate schemes. I say: 'There's next to no chance that I'll recover my losses, I mean, like 1 in a billion; but I still have faith that I will.'

Case 2. Imagine we get together and in the course of our conversation I divulge that my marriage is on the rocks. In fact, I tell you, it is beyond being on the rocks; it's dashed to smithereens on the rocks. I say: 'Although it's not absolutely certain that she's going to leave me, it's as certain as tomorrow's sunrise. Even so, I have faith that she'll stay with me.'

Case 3. Imagine that I disclose to you, my dearest friend, in a heart-to-heart exchange: 'Sometimes, when I'm out hiking by myself and it's late at night and I'm looking up at the stars and the arguments of my atheistic friends scroll through my mind, you know, it crashes on me like a stack of bricks: this God stuff is about as good a bet as a Powerball ticket next Wednesday - 1 in 300 million. Nevertheless, I have faith that God exists.'

You would be perplexed, bewildered, and suspicious about what I said. 'How weird, how strange', you'd think to yourself, 'Why would he say such a thing? Surely he doesn't mean to attribute faith to himself, not strictly speaking.' That's because, given standard uses of 'faith that $p$ ' in modern English, and given standard uses of the probabilistic language I'm using, having faith that those things are the case is at odds with the probability I've assigned them. But in that case, we have some defeasible reason to think that it is conceptually impossible to have faith that $p$ while assigning such low probability to $p$. And so we have defeasible reason to think that for you to have faith that $p$ on the basis of assigning a probability to $p$ is, in part, for you to assign a significantly higher probability to $p$ than Buchak 2018* allows. Defeasible evidence; still, some evidence.

Third, if Smith has faith that the BCS is true, then she has a positive cognitive attitude towards the BCS, and so she will not be strongly inclined to think that the BCS is false; but anyone who assigns 1 /googolplexian to $\operatorname{Pr}(\mathrm{BCS} / \mathrm{E})$ will be so inclined. 
Fourth, you can't have faith that $p$ if you disbelieve $p$. If Smith assigns $\operatorname{Pr}(\mathrm{BCS} / \mathrm{E})$ a value of 1 /googolplexian, and if she is capable of disbelief on the matter (suppose she is), then Smith disbelieves BCS.

Fifth, if you have faith that $p$, then you have a positive cognitive attitude towards $p$, in which case that attitude has a mind-to-world direction of fit: it is how it ought to be only if $p$ is true. Suppose Smith has exactly two attitudes towards the BCS: (i) $\operatorname{Pr}(\mathrm{BCS} / \mathrm{E})=1 /$ googolplexian and (ii) $\operatorname{Pr}($ not $-\mathrm{BCS} / \mathrm{E})=1-1 /$ googolplexian. As for (i), it is not how it ought to be only if $p$ is true. As for (ii), it is how it ought to be only if $p$ is false, or close enough as to make no difference. So, Smith has no positive cognitive attitude towards $p$, and so Smith lacks faith that $p$.

Sixth, you have faith that $p$ only if you are not disposed to assert not- $p$ if asked. Smith is disposed to assert not-BCS if asked. So Smith does not have faith that BCS.

Upshot: faith entails a more positive cognitive attitude towards its object than Buchak 2018* allows. How much more positive is up for debate, although there are non-trivial constraints imposed by the concept of faith and faith's positive cognitive attitude requirement.

However: one might think differently about the matter. Yes, on Buchak's later theory and on Buchak 2018*, Smith has faith that BCS even though, for them, Pr $(\mathrm{BCS} / \mathrm{E})=1$ /googolplexian. What's the big deal? Here are four reasons to think that's perfectly fine.

First, Smith doesn't disbelieve BCS. If Smith believes that BCS is false, we should expect that she will tend to (i) assert this, (ii) behave in ways appropriate to BCS not being the case, and (iii) represent reality to herself in this way. ${ }^{58}$ Yet none of these characterizes Smith. On the contrary, as a matter of considered judgement, she refuses to assert that BCS is false and deliberately acts on the assumption that it is true.

Second, it might even be the case (though it need not be) that Smith believes BCS. According to Richard Swinburne among others, belief is contrastive. ${ }^{59}$ That is, for you to believe that $p$ is for you to believe that $p$ is more likely than each of its contraries. Typically, the contrary is not- $p$, but not always. In some contexts, a variety of contraries might be salient. Consider the NBA. Suppose you give the Lakers a $20 \%$ chance of winning the title next year. However, you give each of the other teams even less of a chance: Clippers (15\%), Rockets (10\%), Bucks (10\%), 76ers (5\%), Celtics (5\%), and so on down to the lowly Knicks (0.1\%). Suppose each of these contraries is salient for you. Then, on Swinburne's view, you believe that the Lakers will win - even though you give them just a $20 \%$ chance.

Most people can't discriminate contraries easily. Smith can. She is the contrastivist's poster child: a contrastive idiot savant. True enough, for her, $\operatorname{Pr}(\mathrm{BCS} / \mathrm{E})=1$ / googolplexian. But that's more than each of BCS's salient contraries, Smith might rightly say. In that case, provided that she doesn't refuse to avow it and the like, Smith believes BCS. Since belief is the paradigmatic positive cognitive attitude and Smith satisfies the other conditions for faith, she has faith that BCS.

Third, faith is a diachronic phenomenon, like other important things, e.g. love. For you to love another is for you to care for their well-being and for you to desire 
personal union with them. ${ }^{60}$ Now, obviously enough, in a marriage that undergoes the usual stresses and strains of life, spouses occasionally have fiery spats that severely attenuate their concern for each other's well-being and abate their desire for personal union. Do they stop loving each other? Of course not. Whether they love each other, even in the pits of marriage, is a diachronic affair, to be seen sub specie aeternitatis, not from the vantage of a moment-bymoment perspective.

The same goes for faith. A person of faith - one who, for example, unifies their entire adult life through the basic Christian story, as we might imagine our friend Smith does - can scrape the bottom of the cognitive trough on occasion, even the 'no way' territory of $\operatorname{Pr}(\mathrm{BCS} / \mathrm{E})=1$ /googolplexian. Does this brief, temporary consequence of, say, too much Laphroaig combined with compelling conversation with atheistic friends mean that Smith lost her faith? Of course not. As with love that matters, so with faith that matters. Whether Smith has faith that BCS, even as her cognitive attitude falls out beneath their feet, is a diachronic affair.

Indeed, we might go further. Suppose we are prepared to allow that someone can remain a person of faith despite a brief walk on the bottom of the cognitive barrel. Why couldn't such walks last a bit longer? And if a bit longer, why not a bit longer still - perhaps spanning the five decades that such doubt apparently accompanied Mother Teresa, arguably an exemplar of faith? In this connection, we would do well to remember that, from a Christian point of view, fifty years is but a moment in the life of each of us; after all, from that point of view, each of us will live forever. ${ }^{61}$

Fourth, to satisfy the cognitive demands of faith that $p$, you need only regard $p$ as a live possibility. That is, you need only to entertain it seriously, not ignore it, and treat $p$ 's probability as non-negligible in theoretical and practical reasoning, and in living your life more generally. Whether $p$ 's probability is negligible for you is, in part, a matter of your values, affections, emotions, and volition; naturally, such things vary from person to person, and it may well vary from time to time and context to context for a single person. Life is full of risks and uncertainties. Some we ignore. The odds of being struck by lightning in your lifetime is 1 / 3000, but no one purchases lightning insurance. Some we choose not to ignore. We check our Powerball ticket, even at 1 in 300 million odds. It's a live possibility for us. Here and elsewhere we sometimes find it useful to distinguish assigning a low probability from flat-out disbelief.

Smith can arguably have faith in the BCS even without contrastive belief of it, indeed even while thinking that naturalism is a good deal more likely. ${ }^{62}$ Suppose she finds the possibility that the basic Christian story is true good and attractive, the pearl of great price. She explicitly disavows belief of naturalism and thus fails to satisfy key conditions or aspects of the dispositional profile often taken to be hallmarks of such belief. Unlike most people in her shoes, she stubbornly refuses to regard BCS's possibility as negligible and she is willing to act on it, to rely on its being true, and to do so with resilience in the face of evidential and non-evidential 
challenges. In that case, it's not only a live possibility for Smith, she has faith that BCS - despite assigning $\operatorname{Pr}(\mathrm{BCS} / \mathrm{E})$ a value of 1 /googolplexian. You satisfy the cognitive condition for faith that $p$ if you assign $p$ enough credence for it to play a role, in combination with your values, in begetting faith-expressive behaviour. If there is a worry about direction of fit, it will also arise at credences of 0.2 or 0.4 . At any rate, Smith's low credence might be accompanied by other positive cognitive attitudes towards BCS that allow her to satisfy faith's cognitive conditions.

Upshot: there are slightly more constraints on the positive cognitive attitude that propositional faith requires towards its object than Buchak 2018* permits, and they allow Smith to have faith that BCS. Three cheers for the art of Smith's life and resilient non-doxastic faith in the face of serious doubt!

So who's right? The voice that spoke in favour of the googleplexian argument or the voice that spoke in favour of the cognitive implications of Buchak 2018*? We leave the matter for further reflection, noting that adjudicating this issue and assessing the plausibility of platitudes that constrain theorizing about faith depend on further unresolved issues about the nature of belief and its relation to credence. Suffice to say, if the first voice is right, then you cannot have faith that $p$ if your credence that $p$ given your evidence is vanishingly close to 0 , and so we have another reason to modify Buchak 2018*.

\section{Looking ahead}

Buchak's early and later theories of faith both merit close attention. They command interest both for the light they shed on the nature of faith and for the implications they have for thinking about the rationality of faith. We sought to advance the conversation by subjecting her theories to constructive scrutiny. What if Buchak took on board our friendly critique? The result would be this:

For $\mathrm{S}$ to have faith that $p$ is (1) for $\mathrm{S}$ to care with positive valence that $p$ and to have a positive cognitive attitude towards $p$, and, as a result, (2) for $\mathrm{S}$ to be disposed to rely on $p$ 's being true, with resilience in the face of evidential or non-evidential challenges to doing so.

And, we can add: the more ways in which $\mathrm{S}$ is disposed to rely on $p$ 's being true, and the more significant those ways are, and the more $S$ is resilient in the face of evidential and non-evidential challenges, the more faith that $p \mathrm{~S}$ has. If this is an advance in our understanding of propositional faith, then we've learned something important by theorizing about faith with Lara Buchak, which was our aim. ${ }^{63}$

\section{References}

Alston, William P. (1996) 'Belief, acceptance, and religious faith', in Jeff Jordan \& Daniel Howard-Snyder (eds) Faith, Freedom, and Rationality (Lanham MD: Rowman \& Littlefield), 3-27. 
BuchaK, LARA (2012) 'Can it be rational to have faith?', in Jake Chandler \& Victoria S. Harrison (eds) Probability in the Philosophy of Religion (Oxford: Oxford University Press), 225-247.

BuCHaK, LaRa (2013) Risk and Rationality (Oxford: Oxford University Press).

Buchaк, Lara (2014) 'Rational faith and justified belief', in Laura Frances Callahan \& Timothy O'Connor (eds) Religious Faith and Intellectual Virtue (Oxford: Oxford University Press), 49-73.

BuchaK, Lara (2015) 'Can it be rational to have faith?', in Louis P. Pojman \& Michael Rea (eds) Philosophy of Religion: An Anthology, 7th edn (Stamford CT: Cengage), 524-541.

ВUСнак, LARA (2017a) 'Faith and steadfastness in the face of counter-evidence', International Journal for Philosophy of Religion, 81, 113-133.

BuCHAK, LaRA (2017b) 'Reason and faith', in William J. Abraham \& Frederick D. Aquino (eds) Oxford Handbook of the Epistemology of Theology (Oxford: Oxford University Press), 46-63.

BuсHAK, LARA (2018) 'When is faith rational?', in Gideon Rosen, Alex Byrne, Joshua Cohen, Elizabeth Harman, \& Seana Shiffrin (eds) Norton Introduction to Philosophy, 2nd edn (New York: W. W. Norton), 115-129.

Dormandy, Katherine (2018) 'Evidence-seeking as an expression of faith', American Catholic Philosophical Quarterly, 92, 409-428.

Grice, H. PAUL (1975) 'Logic and conversation', in Peter Cole \& Jerry L. Morgan (eds) Syntax and Semantics, III: Speech Acts (New York: Academic Press), 41-58.

HACKING, IAN (2006) The Emergence of Probability, 2nd edn (New York: Cambridge University Press).

Hájek, Alan \& Lin, Hanti (2017) 'A tale of two epistemologies?', Res Philosophica, 94, 207-232.

Horgan, Terry (2017) 'Troubles for formal epistemology', Res Philosophica, 94, 233-255.

Howard-Snyder, Daniel (2013) 'Propositional faith: what it is and what it is not', American Philosophical Quarterly, 50, 357-372.

Howard-SNyder, Daniel (2016) Does faith entail belief?', Faith and Philosophy, 33, 142-162.

HoWARD-SNYDER, DANIEL (2017) 'Markan faith', International Journal for Philosophy of Religion, 81, 31-60.

Howard-SNyder, Daniel (2018) 'Three arguments to think that faith does not entail belief', Pacific Philosophical Quarterly, 100, 114-128.

Howard-SNyder, Daniel (2019) 'Can fictionalists have faith? It all depends', Religious Studies, 55, 447-468.

Howard-Snyder, Daniel \& McKaughan, Daniel J. (2020) 'Faith and humility: conflict or concord?', in Mark Alfano, Michael Lynch, \& Alessandra Tanesini (eds) Handbook of the Philosophy of Humility (New York: Routledge), 212-224.

Howard-Snyder, Daniel \& McKaughan, Daniel J. (unpublished) 'Relying on someone for something'.

Kvanvig, Jonathan (2018) Faith and Humility (Oxford: Oxford University Press).

LewIS, C. S. (1942/2015) The Screwtape Letters (London: Geoffrey Bles; New York: HarperOne).

Matheson, Jonathan (2018) 'Gritty faith', American Catholic Philosophical Quarterly, 92, 499-513.

McKaughan, Daniel J. (2013) 'Authentic faith and acknowledged risk: dissolving the problem of faith and reason', Religious Studies, 49, 101-124.

McKaughan, Daniel J. (2016) 'Action-centered faith, doubt, and rationality', Journal of Philosophical Research, 41, 71-90.

McKaughan, Daniel J. (2017) 'On the value of faith and faithfulness', International Journal for Philosophy of Religion, 81, 7-29.

McKaughan, Daniel J. (2018) 'Faith through the dark of night', Faith and Philosophy, 35, 195-218.

McKaughan, Daniel J., \& Howard-Snyder, Daniel (forthcoming) 'Faith', in Stewart Goetz \& Charles Taliaferro (eds) The Encyclopedia of Philosophy of Religion (New York: Wiley-Blackwell).

McKaughan, Daniel J., \& Howard-Snyder, Daniel (unpublished a) 'How does faith relate to faithfulness?'.

McKaughan, Daniel J., \& Howard-Snyder, Daniel (unpublished b) 'How does trust relate to faith?'

Morgan, TERESA (2015) Roman Faith and Christian Faith: Pistis and Fides in the Early Roman Empire and the Early Churches (New York: Oxford University Press).

Preston-Roedder, Ryan (2018) 'Three varieties of faith', Philosophical Topics, 46, 173-199.

Stump, Eleonore (2010) Wandering in Darkness: Narrative and the Problem of Evil (New York: Oxford University Press).

Swinburne, Richard (2005) Faith and Reason, 2nd edn (Oxford: Oxford University Press).

WASSERMAN, Ryan (unpublished) 'Against doxastic reductionism'. 


\section{Notes}

1. Buchak (2012), 226; Idem (2014), 52.

2. Buchak (2012), 234.

3. Ibid., 226-227.

4. Buchak (2017a), 115, 120-123.

5. Buchak (2014), 49; Idem (2017b), 58.

6. Buchak (2017a), 114; Idem (2018), 117, 121. However, in Buchak (2012, 229, n. 5), we read: 'In some of the analyses under review here the act does not figure into the proposal. Therefore, for readability, I will say "faith in X" when I really mean "faith that X expressed by A, for some particular A".' We suggest in the text that the more plausible reading is the one we select for assessment.

7. Buchak (2012), 226, 228.

8. For Buchak's terminology, see Buchak (2013), 6-9.

9. Buchak (2012), 228, emphasis added; Buchak (2015), 526, emphasis added.

10. Buchak (2014), 52; Idem (2018), 115-116.

11. We distinguish Buchak (2012), the paper, from Buchak's early theory, the 'final analysis' quoted from Buchak (2012); and we distinguish each of them from Buchak 2012*, our focus here.

12. Regarding the act of relying on someone for something, as well as the act of relying on $p$ 's being true, see Howard-Snyder and McKaughan (unpublished).

13. For example, Kvanvig (2018). For critique, see McKaughan \& Howard-Snyder (unpublished a).

14. Buchak (2012), 230, 234.

15. Alston (1996), 13.

16. For a brief critique of Thomistic theories, see Howard-Snyder and McKaughan (2020). For a critique of other cognitively demanding theories see Howard-Snyder (2013), (2016), (2017), and McKaughan (2013), (2016), (2018).

17. Buchak (2012), 226.

18. Buchak (2012), 226; cf. (2014), 53; (2017a), 114.

19. Cf. Alston (1996), 12.

20. Cf. Howard-Snyder (2013), 362.

21. Cf. ibid., 363.

22. Cf. ibid.

23. Buchak (2012), 234, 237, 244.

24. Preston-Roedder (2018).

25. Morgan (2015), 120.

26. For a fuller discussion of the value of faith and faithfulness, see McKaughan (2017) and McKaughan \& Howard-Snyder (unpublished a).

27. Cf. Howard-Snyder (2017), 48.

28. For present purposes, to disbelieve $p$ is to believe not- $p$, not merely to lack belief that $p$.

29. Cf. Howard-Snyder (2018).

30. For present purposes, to disbelieve $p$ is to believe not- $p$. (For dissent, see Wasserman (unpublished).) In that case, one may well think that, far from being a platitude, it is false that faith that $p$ is incompatible with disbelieving $p$. After all, one might say, faith that $p$ is no more incompatible with disbelieving $p$ than belief that $p$ is incompatible with believing not- $p$. Which is to say that they aren't incompatible at all. By way of reply, two thoughts. First, there are plausible dispositional accounts of belief that entail that believing $p$ is incompatible with believing not- $p$, but we don't want to put all our eggs in that basket. Second, consider the claim that faith that $p$ is incompatible with disbelieving $p$ when disbelieving $p$ is the only or dominant cognitive attitude one has toward $p$. That allows for the compatibility of faith that $p$ and disbelieving $\mathrm{p}$, while focusing our attention on what we regard as the more important, normal case. This is how we'll understand the platitude in the text and in what follows.

31. Buchak (2012), 228, 233-234, 236-238, 240, 242-245; Idem (2013), passim; Idem (2014), 53, 54, 55, 57, 6566, 70; Idem (2015), 228, 233-234, 236-238, 240, 242-245; Idem (2017a), 116-126; Idem (2018), 119, 122, $124,127$.

32. Buchak (2012), 226

33. Ibid., 227. 
34. Buchak (2018), 117. We'll focus on the later theory as presented in Buchak (2018), but compare her account of what it is for an act to be an act of faith in Buchak (2017a), 115.

35. Buchak (2018), 121-122, 124; see also 'act faithfully' (ibid., 118) and 'faithful person' (ibid., 128).

36. This addition first appears in Buchak (2014), 53: a person has faith that $p$ only if they 'have a positive attitude towards the truth of the proposition'. However, there the positive attitude requirement supplements the caring requirement: someone has faith that $p$ only if they 'care whether or not the proposition is true' (ibid.). By Buchak (2018), these distinct requirements appear to collapse into one, which seems sensible.

37. As we pointed out earlier, the last two additions were present in the commentary in Buchak (2012), but they were omitted from the 'final analysis', quoted above as Buchak's early theory.

38. Cf. Howard-Snyder (2017), 36-47; Idem (2019), 450; Kvanvig (2018), 17; Matheson (2018), passim; McKaughan (2018), 202; McKaughan \& Howard-Snyder (forthcoming).

39. Lewis (1942/2015), 38-40.

40. Buchak might be sympathetic to this idea; see Buchak (2017a), 120 n. 14.

41. Buchak (2018), 117, emphasis added.

42. Ibid., emphasis added; cf. Buchak (2017a), 114.

43. Buchak (2017a), 114, emphasis added; Buchak (2017a), 113, emphasis added; Buchak (2014), 54 emphasis added; cf. Buchak (2017a), 115.

44. Buchak (2017a), 115.

45. Buchak (2014), 54 n. 5.

46. Buchak (2012), 227; cf. Buchak (2014), 53.

47. Grice (1975).

48. Buchak (2012), 232-233.

49. Buchak (2014), 49.

50. Buchak (2017b), 58.

51. Buchak (2012), 233.

52. For Envelope in film, with a cellphone instead of an envelope, see False Flag, Season 1, Episode 3, 26:40ff.

53. Buchak says that what we envision here is not a way of expressing faith:

consider the person who intends to open the private investigator's envelope publicly, precisely to show that he has faith in his spouse's constancy. On the current analysis, neither of these acts can be acts of faith: indeed, performing them entails that the agent does not have faith in the proposition in question. (Buchak (2012), 234)

Dormandy (2018), 414-422, agrees with us and makes a similar point to ours, although much more thoroughly, with an extensive analysis of Job.

54. Buchak (2017a), 129, emphasis added.

55. Buchak (2014), 49-50; 72 n. 1.

56. Ibid., 50 .

57. Hacking (2006).

58. Cf. Alston (1996), 4.

59. Swinburne (2005), 5-7.

6o. Cf. Stump (2010).

61. On the faith of Mother Teresa, see McKaughan (2018).

62. Cf. McKaughan (2016).

63. A grant from the John Templeton Foundation supported this publication. The opinions expressed in it are those of the author(s) and might not reflect the views of the John Templeton Foundation. We also thank Lara Buchak, Frances Howard-Snyder, Hud Hudson, Christian Lee, Neal Tognazzini, Ryan Wasserman, Dennis Whitcomb, and, most especially, Professor Dr Bruno Niederbacher SJ, Department of Christian Philosophy, University of Innsbruck, for extraordinarily helpful comments. 